\title{
The Role of the National Institute of Library and Information Sciences to Empower Teacher Librarians in Sri Lanka
}

\author{
Ranaweeragei Prasanna P.R. \\ National Institute of Library and Information Sciences, University of Colombo \\ Colombo 03 \\ Sri Lanka \\ prasanna_ranaweera@yahoo.com
}

\begin{abstract}
The National Institute of Library and Information Sciences (NILIS), an Institute affiliated with the University of Colombo, in Sri Lanka, was established in 1999, with the main objective of training Sri Lankan school librarians and other library staff, under the World Bank project. Accordingly, in 2002, NILIS commenced Certificate, Diploma, and Post-graduate courses for teacher librarians. Concurrently the Ministry of Education selected and trained 4000 teacher librarians with the assistance of NILIS. The training consisted of short term and long term programs commencing at the certificate level and leading to the post graduate level . Teacher librarians were mainly trained to manage school libraries; while being empowered to teach the subjects in which they specialized in the university, or Information literacy, in order to give them the same status as the other teachers. To date NILIS has trained around 2000 teacher librarians under the different categories. In this study, the number of training sessions conducted, number of teachers trained, and the outcome of the programs are elaborated and discussed. Finally, the performance of the teacher librarians after the completion of the masters in teacher librarianship course conducted by NILIS is critically discussed, using the data collected by the interview method with the random sampling technique. The results show that most of the teacher librarians trained at NILIS are performing school library organization activities at a more satisfactory level than prior to receiving their training. Nevertheless, the teaching of information literacy by the teacher librarians to the school children is not being fulfilled at a satisfactory level. Most of the teacher librarians who have obtained higher professional qualifications at NILIS are unsatisfied due to problems with regard to their promotional schemes. Since 2005, NILIS and other relevant bodies have been striving to resolve the problems of the teacher librarians, but so far their efforts have not been successful.
\end{abstract}

Key words: Teacher Librarians, NILIS, School Libraries-Sri Lanka

\section{Introduction}

The school library or Library and Information Resource Centre is considered as the nucleus of the school education system. With the explosion of a variety of information and information sources, the role of the traditional school library and the school /Teacher librarian has changed drastically. Teacher librarians have been identified in the $21^{\text {st }}$ century as the teachers, instructional partners, information specialists, program administrators, and leaders in the school. The teacher librarians "empower students to be critical thinkers, enthusiastic readers, skillful researchers, and ethical users of information" (Empowering Learners, 2009, p. 8). The teaching and leadership role of the school/Teacher Librarian was emphasized by the American Association of School Librarians (AASL) School library media specialists should initiate advocacy programs to promote the school library media program as essential to teaching and learning (AASL, 2009). 
To achieve the best results from the school library, some variables have been identified in the literature; such as the teaching style of the classroom teacher, the quality of the school library collection, the effectiveness of the school library facility, the level of expertise of the teacher-librarian, the school culture, the instructional leadership of the principal and the previous training and experience of the staff, etc. In this study, the focus is on the training and education of teacher librarians.

Teacher-librarian is defined as: "A professional teacher with a minimum of two years of successful classroom experience and additional qualifications in the selection, management and utilization of learning resources, who manages the school library and works with other teachers to design and implement resourcebased instructional programs (Asselin, Branch \& Oberg, 2003, p. 84).

\section{The National Institute of Library and Information Science}

The National Institute of Library and Information Science (NILIS), affiliated to the University of Colombo, Sri Lanka. One of the main objectives of the institute is to provide postgraduate education and general training facilities in the Library and Information Science field, with special attention to the school/teacher librarians and staff. The NILIS courses have been designed not only to teach school library organization and management, but also to teach how information resources could be used effectively and efficiently, for teaching and learning purposes.

The establishment of the institute was initiated with the World Bank funded General Education Project 2, (GEP 2). The GEP 2 project (1993-2003) focused mainly on improving the different education sectors in Sri Lanka including the School Library sector. The traditional teacher centered rote learning method that prevailed in Sri Lankan schools needed to be changed to new resource based student centered school education. Under the GEP 2 project, 4000 school libraries were developed to facilitate resources based school education. Therefore the necessity arose to train and equip with the higher qualifications, the newly recruited 4000 school librarians, and other obligatory human resources needed for the newly developed 4000 school libraries. Thus the need arose to establish a training institute affiliated with a university to train the teacher librarians. Concurrently, in order to develop the school libraries in Sri Lanka, the School Library Development Unit (SLDU) was established under the Ministry of Education. SLDU, in collaboration with NILIS, conducts many training sessions for teacher librarians, teachers, principals, and subject directors, with the objective of promoting resource based education throughout the Island, in addition to its school library administrative process. NILIS was established in 1999 by an ordinance under section 18 and 24 of the Universities Act No. 16 of 1978, as an institution affiliated to the University of Colombo. NILIS is located in the faculty of Education premises of the University of Colombo and has been given authority by the Ordinance to perform a number of functions; such as to admit students, to provide instruction, training, and research in LIS subject areas, to determine postgraduate degrees, diplomas, certificates, and other academic distinctions to be awarded in LIS, to conduct examinations, and award degrees. One of the primary objectives of the institute is to train the human resources required for the vast school library sector in the country. In addition to the above, NILIS is empowered to conduct other postgraduate programs in the Library and Information Science (LIS) field and produce the necessary high quality human resources for the universities, research institutes, government departments, local government authorities, and other library and information sectors in the country. Another major objective of NILIS is to conduct continuing professional development (CPD) programs for LIS professionals to enable them to update and upgrade their skills and knowledge.

The University Grants Commission (UGC) of Sri Lanka is the main controlling body of NILIS. The Director of NILIS is appointed by the UGC upon the recommendation of the 
Board of Management. The NILIS board of Management is the executive body which administers the property and funds of the institute, and determines all other matters pertaining to the institute. The Director is the principal academic, administrative, and accounting officer of NILIS . Recommendations for the NILS academic activities are made by the academic committee, which are finally approved and recommended by the Council and Senate of the University of Colombo.

According to the modern education concept, the school library is the focal point in developing school students' Independent Learning Skills and Resource-Based Learning programs. In keeping with these main objectives, NILIS has designed all its courses to meet the requirements of teacher librarians and school librarians. NILIS commenced its' teaching and training programs in January 2002 with a three days workshop for the training of teacher librarians. In 2002 and 2003 NILIS completed a five-day workshop for the 2800 teacher librarians, in collaboration with the Ministry of Education. At these workshops, teachers and teacher librarians were given a basic understanding of the role of the teacher librarian, collection development, cataloguing, classification, library management, reading promotion and developing information skills of students, circulation and other reader services and methods of evaluating school library services. The manual written by the subject experts was used by the trainers conducting the workshops, in order to maintain the same standard throughout the Island. NILIS offers the following facilities to students: a fully equipped library with the latest print and electronic resources for teacher librarianship, Audio/ Visual materials related to teacher librarianship, three computer labs, modern lecture theatres, affiliation to the main libraries in the main Colombo city, and qualified permanent and visiting lecturers. In 2002, NILIS commenced its first certificate course which was the Certificate in school library organization and administration (CSOA), with 25 students. In 2003 the CSOA was developed into two courses to cater to the teachers and non-teaching school library staff. One course was named Certificate in School librarianship (CSL), a six-month course for the school library staff, and the other was the Certificate in Teacher Librarianship (CTL), a sixmonth course for teacher librarians. Over 500 teacher librarians and school library staff were trained in both of these courses. The course Information Technology for Teacher Librarians was introduced in 2004. Around 43 teachers followed the course between 2003-2005. Subsequently the ICT skills curriculum was integrated with all the courses at different levels. In 2003, The Diploma in Teacher Librarianship (DTL), a $300 \mathrm{hrs}$ course was commenced for non-graduate trained teachers with 22 students enrolled. In 2011, a new course, the Diploma in school librarianship was commenced with the aim of giving a higher qualification and training to those who completed successfully the CSL and CTL courses. The course commenced with 22 students in 2011, and by 2012 there were 36 students enrolled. 


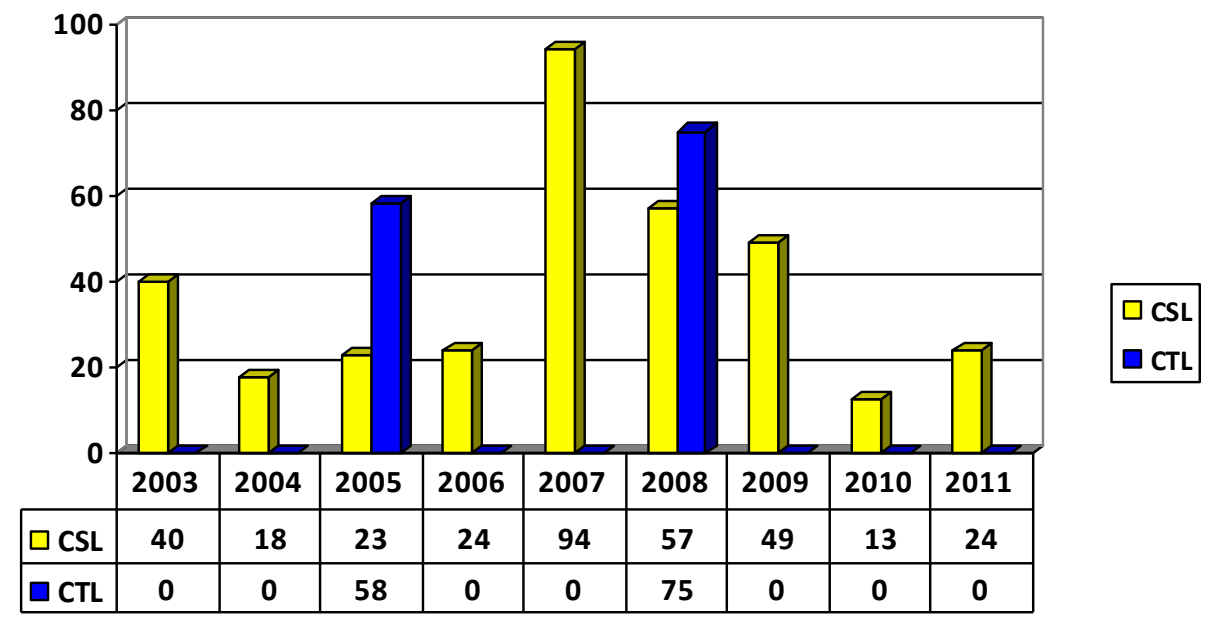

Figure 1. Number of Students that Followed CSL \& CTL Courses

The Postgraduate Diploma in Teacher Librarianship (PGTL) (Full time I year, Part time 2 years) program designed for the teachers with a Degree in any discipline, and selected to work in school libraries, commenced in 2003. This course is being conducted annually on a full time and part time basis, according to the availability of the number of students. Since 2003 up-to 2011, 159 students have followed the course.

The Masters in Teacher Librarianship (MTL) Program (full time) 1 year, (part time) 2 years, is designed for teacher librarians, Educational Administrators and teachers with a Degree in any discipline and PG Diploma in Education/ PGTL. The first batch of students for this course enrolled in 2003. Up to 2012, 107 students have enrolled for the course. The first graduation ceremony of the NILIS first batch of postgraduate students was held in April 2005. The statistics were as follows: Masters in Teacher Librarianship - 18 students, Postgraduate Diploma in Teacher Librarianship -10 students.

The M Phil/PhD Program commenced in 2007 with seven students. In 2012, a teacher librarian who completed his Masters in Teacher Librarianship at NILIS in the English medium in 2007, registered for his PhD.

In addition to the main study courses, NILIS and its academic staff have contributed immensely towards conducting seminars, workshops and training sessions.

The following table depicts the seminars, workshops and training sessions that were conducted in 2012, with the patronage of the school library development unit of the Ministry of Education.

Table 1. Seminars, Workshops and Training Programs in 2012

\begin{tabular}{|l|c|}
\hline Name of program & $\begin{array}{c}\text { Number of } \\
\text { Participants }\end{array}$ \\
\hline $\begin{array}{l}\text { Pre-preparation Workshop on Library officials training for Northern Province } \\
2012.03 .01-02\end{array}$ & 15 \\
\hline $\begin{array}{l}\text { Preparing Manual for Children's Literature (Research program) } \\
2012.03 .01-02\end{array}$ & 40 \\
\hline $\begin{array}{l}\text { Training Program for Teacher Librarians Education Development Centre } \\
2012.03 .19-20\end{array}$ & 40 \\
\hline $\begin{array}{l}\text { Preparing Manual for Children's Literature: Educational Practice Program } \\
2012.04 .23-25\end{array}$ & 40 \\
\hline $\begin{array}{l}\text { Training Program for Principals of Model School Library Learning Resource } \\
\text { Centers in island wide 2012.05.28-30 }\end{array}$ & 18 \\
\hline
\end{tabular}




\begin{tabular}{|l|c|}
\hline Training Program for Teacher Librarians 2012.06.25-26 & 40 \\
\hline $\begin{array}{l}\text { Trainer for Training Program on Subject Related Reading Camp } \\
\text { (Geography) in Southern Province 2012.09.09 }\end{array}$ & 15 \\
\hline $\begin{array}{l}\text { Two day Workshop for Library Teacher and Teacher Librarians } \\
2012.09 .10-11\end{array}$ & 40 \\
\hline $\begin{array}{l}\text { Trainer for Training Program on Subject Related Reading Camp (Science) } \\
\text { Uva Province 2012.09.24-25 }\end{array}$ & 30 \\
\hline $\begin{array}{l}\text { Preparing Manual for Children's Literature: Portfolio Evaluation Program } \\
2012.10 .11-12\end{array}$ & 40 \\
\hline $\begin{array}{l}\text { Trainer for Training Program on Subject Related Reading Camp (Sinhala } \\
\text { Language) North Central Province 2012.10.29 }\end{array}$ & 30 \\
\hline $\begin{array}{l}\text { Pre-preparation Workshop on Library Officials Training in Eastern Province } \\
2012.11 .04-06\end{array}$ & 15 \\
\hline $\begin{array}{l}\text { Trainer for Training Program for Zonal Library Co-ordinators in Northern } \\
\text { Province 2012.11.25-27 }\end{array}$ & 15 \\
\hline Training Supervision Program (Northern Province) 2012.12.28-30 & 15 \\
\hline
\end{tabular}

\section{Empowering 8 Information Literacy model}

Consequent to the tremendous advancements in the Information Age towards the end of the last millennium, it was observed that there was a lacuna in the school and other library sectors with regard to the practical application of the Information Literacy concept in Sri Lanka. NILIS identified this gap and initiated the introduction of the Information Literacy concept by jointly organizing an international workshop with IFLA- ALP in 2004. Delegates representing ten South and Southeast Asian countries and 40 Sri Lankans participated in this workshop.

When a plethora of IL models are already available, one may question why the wheel is being re-invented. Re-inventing the wheel or developing another model is essential because of the composite culture and local conditions in these countries. If an existing model used in a developed country is imposed, it would be difficult for the stakeholders to understand the philosophical roots behind the model. Therefore, the workshop participants, throughout five days worked from identifying the need of IL through comparison of different models to building the E8 to suit the local needs of the region. (Wijetunge 2004)

The E8 model consists of the following components: Identify, Explore, Select, Organize, Create, Present, Assess, and Apply, and it is a cyclical process that can be applied and implemented by all teacher librarians, teachers, and students for their teaching and learning purposes. The model was introduced to the general education system at a ceremony graced by the secretary, Ministry of Education. Since then NILIS has been conducting Information Literacy training programs (based on Empowering 8 model) for Education Administrators, School Principals, Teachers, and Teacher librarians with the collaboration of the School Library Development Unit of the Ministry of Education, and the Provincial Education Departments.

\section{Methodology and Results}

The Teacher Librarians who followed the Masters in Teacher Librarianship (MTL) course conducted by NILIS is the population of this study. The sample for this study was selected from those who followed the MTL, using the probability systematic random sample method. The sampling frame was based on a list of 107 students who had followed the MTL course during 2003-2011. 


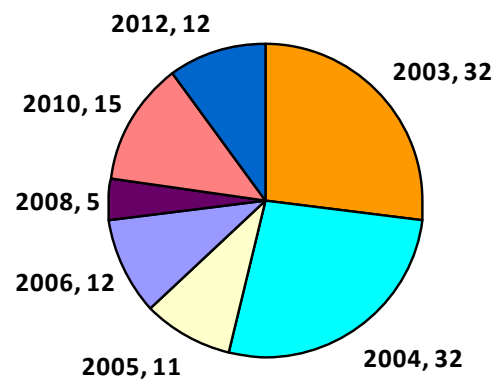

Figure 2. Number of Students that Number of Students that followed MTL Course

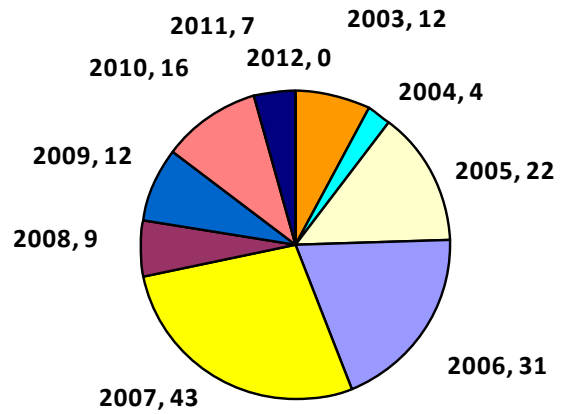

Figure 3. Number of Students that Number of Students that followed PGTL Course

The list was arranged in alphabetical order and the name of every fifth student was selected for the study. Therefore the total random sample was 20. Data collection was done via a telephone interview, to which 12 participants responded. The final sample included nine teacher librarians and three teachers who had followed the MTL course. The respondents included seven female and five male participants.

The results revealed that all participants were happy and satisfied with the MTL course content and the consequent skills they gained during the study period. But they are not happy and satisfied with the facilities and avenues that are available in the school libraries to put into practice what they have learned from the course. All 12 participants expressed their displeasure and dissatisfaction since the MTL qualification has so far not been taken into account in their promotion schemes, unlike the Masters in Education (Med).

One of the main components of the MTL course is developing information literacy skills among the school children by teacher librarians. In the interview the researcher questioned whether the participants had taught information literacy skills to the students. Except three teachers all other nine teacher librarians responded that they had conducted library orientation programs; but teaching information literacy skills for the students had been done only by three teacher librarians. The reason why they could not teach information literacy was because they were assigned to teach other subjects in the school; the respondents did not integrate information literacy skills teaching into their subject related teaching. As highlighted in the instructions to the school principals by the Ministry of Education, assigning teaching responsibilities to the teacher librarians is a favorable sign of recognition of teacher librarians as teachers. Prior to these instructions most teacher librarians were treated as office or administrative staff of the school libraries.

Another question of the researcher was whether the participants had done any library based education programs for the teachers, in order to educate them on how to use library resources for their teaching learning process. This is another area which is given priority in the MTL course. Only one teacher and four teacher librarians had done such programs for the teachers. That too had been done once only, and not continuously. The respondents emphasized that the continuous training sessions are essential to enable the teacher librarians to carry out their duties efficiently.

To the question "Have you motivated teachers to come to the library with the students to perform their resource based teaching and learning?" all respondents replied that although the students come to the library during their library period, they are not accompanied by the teachers because there is inadequate space in the library for teaching. Usually in Sri Lanka a government school class room consists of 50 students.

Initially, the 2003 and 2004 MTL course students were teachers, as during that time the Ministry of education recruited trained graduate teachers to the school libraries. But in 2005, 
when untrained graduates were recruited as teacher librarians, they were assigned to manage the school libraries. This was the scenario which made the teacher librarian concept an enigma. According to the definition of a teacher librarian, he/she should possess at least two years classroom teaching experience. The first batch of teacher librarians who were trained for the school libraries in 2003 were well-qualified, recognized teachers of the schools. Subsequently the recruitment policy was changed to facilitate the appointment of unemployed graduates as teacher librarians. As a result, the previously trained professional teachers turned to their own subject teaching while the newly recruited graduates undertook the duties of the teacher librarians.

\section{Discussion and Conclusion}

With the introduction of the GEP 2 project to the Sri Lankan school libraries the NILIS, SLDU, Teacher librarians, School library and Resource centers, Resource based education and Information literate school community became current topics which brought about a paradigm shift in the Sri Lankan school education system. Although all teacher librarians appointed by the Ministry of Education are required to follow the NILIS post-graduate courses to improve further their professional development, to provide better service to the school community, many are reluctant to follow the NILIS Postgraduate and Masters courses, which have been specially designed for the teacher librarians. They prefer to follow the Post-graduate diploma in teacher librarianship and the Masters in teacher librarianship, which are the stipulated qualifications laid down by the Ministry of Education for their promotions.

All the teacher librarians and teachers who have followed the NILIS courses are appreciative of the course content and the knowledge they have gained; but unfortunately they are dissatisfied, because the environment and the facilities available to them are not appropriate to practice what they have learned. For the past ten years, NILIS, SLDU and stakeholders have been attempting to streamline the promotional scheme of Teacher Librarians who have obtained NILIS postgraduate qualifications, but have been unsuccessful in their attempts. This is an extremely important issue that all stakeholders should work to resolve.

Figures 2 and 3 show that the number of post-graduate students following the teacher librarianship courses conducted by NILIS have been gradually dwindling, and at present are few in number; thereby adversely affecting the school libraries and their development in the future. Urgent remedial action is needed to rectify this situation. All the respondents were unanimous in their opinion that continuous training sessions should be imperative, in order to enable the teacher librarians to carry out their services effectively and efficiently

\section{References}

American Association of School Librarians (AASL). (2009). Empowering learners: Guidelines for school library media specialists. Chicago, IL

Annual reports 2003-2011, National Institute of Library and Information Sciences, University of Colombo

Asselin, M., Branch, J., \& Oberg, D. (Eds.). (2003). Achieving information literacy: Standards for school library programs in Canada. Ottawa, Canada: Canadian School Library Association \& The Association for Teacher-Librarianship in Canada.

Brown, Gerald R. Bowden, Russell and Wijetunge, Pradeepa. (Ed.s) Information Skills for Learning. Proceedings of the International Workshop; 2004 November 01-05. Colombo. IFLA-ALP / NILIS. 
Church, Audrey P. (2011) Models of Leadership, Delta Kappa Gamma Bulletin, Retrieved from http://publication.dkg.org/dsweb/Get/Version-

1256/Spring\%202011_Models\%20of\%20Leadership.pdf

Wijetunge, Pradeepa (2002). Empowering students towards a Knowledge Society through a school library development project: a conceptual model for Sri Lanka. IN: School libraries for a knowledge society. Proceedings of the 31st annual conference of the IASL. Ed. by Diljit Singh ... [et.al.]. Washington. IASL. pp. 251 - 264.

Wijetunge, Pradeepa (2003). The survival of National Institute of Library and Information Sciences in a turbulent public university environment. Malaysian Journal of Library and Information Science, 8(2), 109 -130.

Wijetunge, Pradeepa (2004). Education and Training of Teacher Librarians in Sri Lanka. Asian Library News . 6(2), 24 -29.

\section{Biographical note}

Ranaweeragei Prasanna P.R. has been employed as a Senior Lecturer at the National Institute of Library \& Information Sciences (NILIS), University of Colombo, Sri Lanka, since 2005. While teaching for the post-graduate teacher librarianship courses, he also conducts regular workshops for teacher librarians and teachers, aimed at developing information literacy competencies. He has presented over ten conference papers, under the subject of information literacy, at local and international conferences. At the same time he has published Journal articles in Sri Lankan LIS refereed journals. His academic background includes a Master of Arts degree, and Masters in Library and Information Science, with the B.A. and Diploma in English language. His career in librarianship commenced in 1992 . Since 2011 to date, he has been following a Ph D course at the University of Malaya. 